\title{
A RELAÇÃO ENTRE CONCEITO E OBJETO NA OBRA DE LACAN E UMA HIPÓTESE SOBRE A ADOLESCÊNCIA
}

DANIELA TEIXEIRA DUTRA VIOLA ${ }^{1}$; Orcid: https://orcid.org/0000-0003-0003-1141

\author{
${ }^{1}$ Universidade Federal \\ de São João del-Rei \\ (UFSJ), Departamento \\ de Psicologia, São João \\ del-Rei/MG, Brasil.
}

RESUMO: Este artigo apresenta um exame da proposição de Lacan (19621963/2005) sobre a relação entre a maturação do objeto $a$ na puberdade e a efetiva assimilação do conceito. Mesmo que pouco elaborada na conjuntura teórica em que aparece, essa formulação é de grande importância por permitir conceber a função essencial do pensamento lógico na adolescência. Para compreender essa função, investigamos o contexto teórico em que essa conexão é proposta e rastreamos a relação entre conceito e objeto na obra desse autor. Esse percurso nos leva a constatar a originalidade e a relevância dessa assertiva lacaniana para a abordagem da adolescência.

Palavras-chave: psicanálise; puberdade; adolescência; objeto $a$; conceito.

\begin{abstract}
The relationship between concept and object in Lacan's work and a hypothesis about adolescence. This article presents an examination of Lacan's proposition on the relationship between the maturation of the object $a$ at puberty and the actual assimilation of the concept. Although it is not elaborated in the theoretical conjuncture in which it appears, this formulation is of great importance because it allows us to conceive the essential function of logical thinking in adolescence. To understand this function, we investigate the theoretical context in which this connection is proposed and trace the relationship between concept and object in the author's work. This path leads us to note the originality and relevance of this Lacanian assertion for approaching adolescence.
\end{abstract}

Keywords: psychoanalysis; puberty; adolescence; object $a$; concept.

DOI - http://dx.doi.org/10.1590/S1516-14982019001006

Todo o conteúdo deste periódico, exceto onde estiver identificado, está licenciado sob uma licença Creative Commons (cc by 4.0) 
A presentamos um exame da proposição de Lacan sobre a relação entre a "maturação do objeto $a$ na puberdade" (LACAN, 1962-1963/2005, p. 282) e a assimilação do conceito - termo que ele utiliza em debate com autores da Psicologia e da Lógica, como será demonstrado no decorrer do trabalho. Embora pouco elaborada na conjuntura em que aparece, essa formulação é importante por permitir conceber a função do pensamento lógico na adolescência. Para compreendê-la, investigamos o contexto teórico em que tal conexão é proposta e rastreamos a relação entre conceito e objeto na obra lacaniana. Esse percurso nos leva a constatar a relevância dessa assertiva de Lacan para a abordagem da adolescência, operação subjetiva que envolve o campo do saber e o corpo. ${ }^{1}$

Na adolescência, a não relação sexual cristaliza-se para o sujeito (LACAN, 1974/2003), torna-se questão incontornável, pois não há saber prévio que possibilite lidar com o real que advém com o despertar pubertário. A maturação orgânica, que capacita o corpo ao ato sexual, não é acompanhada de um saber-fazer no encontro sexual. Considerando a adolescência uma resposta subjetiva ao que emerge com a maturação no corpo e escapa ao sentido, é de grande importância a proposição da maturação do pensamento como ferramenta que pode auxiliar o sujeito nessa tarefa.

\section{A ANGÚSTIA DE CASTRAÇÃO E O CAMPO DO PENSAMENTO}

A formulação lacaniana sobre a maturação do objeto $a$ na puberdade se insere na trama teórica do seminário A angústia. O exame desse afeto conduz Lacan (1962-1963/2005) à postulação de um resto lógico da constituição subjetiva, análogo aos apêndices separáveis do corpo. Por concernir ao resíduo da entrada na linguagem, essa maturação não diz respeito a um desenvolvimento cronológico, mas à temporalidade lógica da puberdade, pautada pela angústia de castração, num momento em que o corpo assume um estatuto inédito para o sujeito.

Conforme Lacan, "a causa original é a causa de um traço que se apresenta como vazio" (ibidem, p. 75). 0 sujeito aparece como barrado a partir de um apagamento original. "Todo o posicionamento posterior do sujeito repousa na necessidade de uma reconquista desse não sabido original" (idem). Lacan demarca, dessa forma, a aparição do sujeito como inconsciente, e associa o que chama de "sistema da consciência" e de "meditação cartesiana" "a um objeto isolável, especificado na estrutura" (ibidem, p. 76).

A certeza é associada à angústia, afeto que sinaliza o real. Já o campo do pensamento relaciona-se ao engano. "Dominar o fenômeno através do pensamento é sempre mostrar como se pode fazê-lo de maneira enganosa, é poder reproduzi-lo, ou seja, fazer dele um significante" (LACAN, 1962-1963/2005, p. 89). Como exemplo, Lacan se serve do caso do Pequeno Hans (FREUD, 1909/2015) que, "tão lógico qua nto Aristóteles, formula a equação Todos os seres animados têm falo" (LACAN, 1962-1963/2005, p. 90). Para o autor, essa proposição de Hans é uma afirmativa universal que define o real a partir do impossível. A dimensão enganosa do pensamento está relacionada ao falo como significante e sua apreensão pelas crianças.

Num trabalho anterior, Lacan (1958/1998) associa o falo à razão e ao pensamento. Define-o como o significante privilegiado da clivagem que marca o ser falante, de maneira que a parte do logos conjuga-se com o advento do desejo. O complexo de castração tem uma função de nó, responsável pela instalação de uma posição na partilha dos sexos. Essa função nodal da castração antecipa a ideia da causação do sujeito a partir de um vazio. O falo é o significante do vazio e tem função de simulacro.

Como elemento mediador entre a razão e o desejo, Lacan propõe tomar o falo como algoritmo basilar na determinação da posição do sujeito na sexualidade. Ainda não contando com a teoria da sexuação, ele atribui essa tomada de posição às relações do sujeito "em torno de um ser e de um ter que, por se reportarem

\footnotetext{
${ }^{1}$ Trata-se de um desenvolvimento teórico extraído da pesquisa de doutorado em Psicologia que teve como objetivo principal compreender as relações do sujeito adolescente com o saber. (Observação: a tese não será citada explicitamente para preservar o anonimato da autoria.)
} 
a um significante, o falo, têm o efeito contrário de, por um lado, dar realidade ao sujeito nesse significante e, por outro, irrealizar as relações a serem significadas" (ibidem, p. 701). Essa irrealidade das relações do sujeito com a sexualidade condiz com a estrutura de ficção da cadeia significante e com a dimensão enganosa do pensamento e da razão.

Essa concepção do significante fálico não conta ainda com a formulação do objeto $a$, ao qual o falo, em sua vertente de objeto cedível, vai se remeter. Mesmo assim, a função lógica do falo como significante antecipa, em certa medida, o que está em jogo nas reflexões lacanianas posteriores sobre o pensamento. 0 saber tem uma face de tropeço que deriva dessa constituição ficcional da linguagem, cuja significação mais radical é um simulacro, o falo.

Nesse sentido, Lacan (1960/1998) recusa a concepção psicológica de uma unidade subjetiva que pressupõe um sujeito do conhecimento. Há um ponto de ignorância elementar que vai ao encontro da fronteira entre a verdade e o saber. "A verdade não é outra coisa senão o que o saber só pode aprender que sabe ao pôr em ação sua ignorância" (LACAN, 1960/1998, p. 812). Ao contrário da unidade do sujeito prevista pela psicologia, ele concebe o sujeito dividido, cuja estrutura significante é marcada por uma descontinuidade no real.

Em função de sua condição estrutural, o complexo de castração é a margem que todo o pensamento evitou ou encobriu. O significante fálico simboliza um gozo ao mesmo passo que o vela - gozo ao qual o sujeito, submetido à lei e ao princípio do prazer, só tem acesso nas entrelinhas da linguagem. Esse algoritmo corresponde ao índice do que faz limite ao gozo. "É a simples indicação desse gozo em sua infinitude que comporta a marca de sua proibição e, para constituir essa marca, implica um sacrifício: o que cabe num único e mesmo ato, com a escolha de seu símbolo, o falo" (ibidem, p. 836).

Esse movimento teórico circunscreve a relação lógica entre o vazio, contornado nesse contexto pela significação do falo, e o pensamento, na esteira da relação entre o sujeito e o saber. Constata-se uma operação de sacrifício, representada e velada pelo falo, como limitação do gozo que inscreve o saber e enseja o cogito. A angústia de castração está no cerne dessas conexões. Com a formalização do objeto $a$, a função algorítmica do vazio é atualizada de modo vigoroso por meio da função lógica da falta, a causa.

\section{A FUNÇÃO DA CAUSA}

Conforme Lacan, a relação com a falta é inerente à constituição de qualquer lógica. A falta radical na constituição do sujeito é enunciada com a formulação: “a partir do momento em que isso é sabido, em que algo chega ao saber, há alguma coisa perdida, e a maneira mais segura de abordar esse algo perdido é concebê-lo como um pedaço do corpo" (LACAN, 1962-1963/2005, p. 149). A separação de certa parte do corpo torna-se simbólica de uma relação fundamental com o próprio corpo, para o sujeito que, desde então, não tem acesso a um saber. Lacan conecta "nosso ser de pensamento" ao "pedaço carnal arrancado de nós mesmos" (ibidem, p. 237). Situa a função da causa na "parte de nossa carne que permanece necessariamente aprisionada na máquina formal" (idem). Esse objeto perdido nos diferentes níveis da experiência corporal em que se produz seu corte é o que constitui o suporte de toda função de causa.

Lacan assinala que "a causa é a sombra ou a contrapartida daquilo que é um ponto cego na função do conhecimento" (LACAN, 1962-1963/2005, p. 239), uma espécie de motor oculto. Para ele, "o homem que fala, o sujeito, a partir do momento em que fala, já está implicado por essa fala em seu corpo. A raiz do conhecimento é esse engajamento no corpo" (ibidem, p. 241). Esse engajamento não deve ser tomado a partir da concepção de um dualismo mente-corpo, ou da ideia do corpo como uma espécie de avesso das funções da mente. O que interessa não é o corpo em sua totalidade, mas, sim, o engajamento do ser falante na cadeia significante. "Sempre há no corpo, em virtude desse engajamento na dialética significante, algo de separado, algo de sacrificado" (ibidem, p. 242). A função do conhecimento está relacionada a uma perda que engendra a complexidade da relação entre o corpo e o significante. 
A questão do conhecimento abre caminho para a interpelação do campo da Pedagogia e da Psicologia. A partir de trabalhos sobre a linguagem e o pensamento, Lacan interroga a transmissão dos conceitos psicanalíticos e os limites de sua compreensão. "Na análise, na técnica analítica, [...] devemos deparar, na elaboração dos conceitos, com o mesmo obstáculo reconhecido como o que constitui os limites da experiência analítica - a saber, a angústia de castração" (LACAN, 1962-1963/2005, p. 281). Com isso, chega ao problema da relação do ensino escolar com a maturação do pensamento da criança.

Localizando um limite a partir do qual o ensino pode ser considerado como evitável, Lacan alude à compreensão matemática: “Conceitos que teriam parecido extremamente complicados, numa etapa anterior da matemática, são imediatamente acessíveis a espíritos muito jovens" (ibidem, p. 282). Mas isso corresponde ao nível científico. Na idade escolar, por seu turno, as coisas não funcionam assim. Para ele, o interesse da pedagogia nessa idade deve estar em captar o ponto vivo, promovendo as capacidades mentais da criança através de problemas que as ultrapassem ligeiramente.

Ao ajudar a criança a abordar esses problemas, apenas ao ajudá-la, quero dizer, faz-se algo que tem não só um efeito prematurador, um efeito de pressa no amadurecimento mental, mas que, em certos períodos chamados sensíveis, [...], permite obter verdadeiros efeitos de abertura ou de desencadeamento. Algumas atividades de apreensão têm, em certos campos, efeitos de fecundidade absolutamente excepcionais. (Idem).

O que vem em seguida remete-nos ao ponto vivo invocado há pouco. Lacan afirma:

O fato de um dado pedagogo ter formulado que só há verdadeiro acesso aos conceitos a partir da idade da puberdade mereceria que acrescentássemos nosso olhar, que metêssemos nosso nariz nisso. Há milhares de indícios sensíveis de que o momento em que realmente começa o funcionamento do conceito, e que os autores chamam - no caso, por uma homonímia puramente fortuita com o termo complexo, do qual nos servimos - de momento-limite complexual, poderia ser situado de maneira totalmente diversa, em função de um vínculo a ser estabelecido entre a maturação do objeto $a$, tal como eu o defino, e a idade da puberdade. (LACAN, 1962-1963/2005, p. 282).

É a emergência de um vazio relacionado ao ponto vivo do sujeito que viabiliza a apreensão dos conceitos. Nesse contexto, Lacan não explicita o teórico em quem se apoia para sustentar essa afirmação, mas sabemos se tratar de Vygotsky (1931/2012) - que defende que só há formação dos verdadeiros conceitos a partir da puberdade e que voltará a ser convocado num seminário posterior, como veremos mais à frente.

Logo após essa proposição, Lacan aborda a angústia de castração, momento lógico em que o objeto $a$ passa por (-ф). O esvaecimento da função fálica justamente no nível em que se espera que o falo funcione constitui o princípio da angústia de castração. Esta é atualizada de forma proeminente na puberdade, como retomada da lógica fálica por um sujeito que, diferentemente da criança no tempo que precede o declínio do Édipo, já está de posse de um saber sobre a diferença sexual, um saber enigmático, que o angustia e desestabiliza. A função fálica e a inauguração, para o sujeito adolescente, do encontro sexual - incluindo aí a experiência do orgasmo - configuram um drama na medida em que se deposita toda a confiança na consumação genital. "É por não realizar o encontro dos desejos, a não ser em seu desvanecimento, que o falo se torna o lugar comum da angústia" (LACAN, 1962-1963/2005, p. 290). Lembrando a função algorítmica que Lacan atribui ao falo, como compreender a abertura conceitual proporcionada por esse movimento pautado por $(-\phi)$ ?

Para Coelho dos Santos, a maturação do objeto $a$ decorre da promoção do falo na relação entre os sexos. Trata-se da tradução lacaniana do que Freud (1905/1996) chamou de "reencontro com o objeto" na puberdade. A autora acrescenta:

Admito, por hipótese, que a significação do falo é responsável pelo aparecimento do conceito e requer o ultrapassamento das consequências psíquicas da diferença anatômica entre os sexos. É preciso que entre em jogo a função essencial do vazio para que se possa entrar no universo dos semblantes - isto é, dos papeis 
sexuais em jogo na encenação da vida amorosa - por uma via diferente do imaginário. (COELHO DOS SANTOS, 2009, s.p.).

Depreende-se a função do vazio para o acesso aos conceitos. A "entrada no universo dos semblantes" está associada à subjetivação da diferença sexual. E os semblantes "homem" e "mulher", resultantes da promoção do falo nesse momento, podem ser tomados como os primeiros conceitos, para além da imagem fálica predominante até então, inaugurando uma nova maneira de lidar com toda a conceituação. Nessa perspectiva, Coelho dos Santos propõe que o acesso aos conceitos depende de uma operação lógica em que a significação do falo se vincula à assimilação da dissimetria entre os sexos.

Ainda no seminário $A$ angústia, Lacan recapitula a função algébrica da causa: um resíduo da função significante em razão da constituição do sujeito como barrado. Propondo um avanço nesse entendimento, demonstra que a causa concernente à função radical do objeto a relaciona-se com a dimensão mental da causa, que equivale ao reconhecimento de que algo funciona de determinada maneira. Essa dimensão é evidente, por exemplo, no sintoma, que só se constitui quando o sujeito se apercebe dele. Para que o sintoma saia do estado de enigma não formulado, é preciso "que se desenhe no sujeito uma coisa tal que lhe seja sugerido que há uma causa disso" (LACAN, 1962-1963/2005, p. 306). Por conseguinte, o objeto a não diz respeito apenas a uma etapa arcaica do desenvolvimento, mas continua em jogo na subjetividade como um motor latente, como causação.

Pois bem, vejamos em que consiste o conceito para Lacan nesse contexto teórico. O nível da fase fálica é central em relação aos diversos estágios do objeto, ocupando uma posição extrema - ou seja, a função fálica impõe-se a todas as formas do objeto. Nesse nível, a função do a é representada pela "falta do falo como constitutiva da disjunção que une o desejo ao gozo" (LACAN, 1962-1963/2005, p. 321). Trata-se da angústia de castração em seu auge, que propulsiona o declínio do complexo de Édipo, encerrando a fase fálica da infância, e que se atualiza de modo inapelável na promoção do significante fálico na puberdade. Prosseguindo nessa elaboração, Lacan afirma:

A causa, para subsistir em sua função mental, sempre necessita da existência de uma hiância entre ela e seu efeito. Essa hiância é tão necessária que, para poder continuar a pensar na causa ali onde ela correria o risco de ser preenchida, precisamos fazer com que subsista um véu sobre o determinismo rigoroso, sobre as ligações mediante as quais a causa age. (Ibidem, p. 322).

Depreende-se a concepção de conceito como o que liga um real a um significante por meio de uma relação funcional que se sustenta num vazio - daí a complexidade do que seria um verdadeiro acesso ao conceito, já que essa ilação lógica não é evidente até se atingir certo grau de "familiaridade" com esse vazio.

A causa é associada a uma hiância porque, em sua forma primária, é causa do desejo, isto é, é causa de algo essencialmente não efetuado. Lacan exemplifica essa não efetuação ao lembrar que, no caso do nível anal, não se pode confundir o excremento com o efeito do desejo anal num sentido de "isso fez efeito?" (idem). O excremento é a causa do desejo anal. Lembrando que o objeto a subsiste sob modalidades diversas, destaca-se a importância de sua função. É disto que se trata na causação: do funcionamento, de algo que faz operar. Por conseguinte, a compreensão só pode se efetivar pela via de uma assunção significante que suscita a apreensão de uma função num nível libidinal. É nesse sentido que Lacan salienta o fato de que a criança pequena fala, mesmo sem saber o que diz. O que comanda o funcionamento da fala nesse nível é o fato da fala em si, que tem como causação o objeto a - comando que remete ao substrato libidinal da linguagem. Mas a fala das crianças nesse nível não garante o acesso aos conceitos.

Nessa elaboração sobre o pensamento das crianças, Lacan comenta um estudo de Piaget (1923/1999). No experimento da "torneira de Piaget", o experimentador dá a uma criança uma breve explicação esquemática sobre o funcionamento de uma torneira. Essa criança primeiramente tem que repetir a explicação ao experimentador e depois deve transmiti-la, como "explicadora", a outra criança, a 
"reprodutora". Piaget se surpreende com a diferença entre uma e outra narração, pois a primeira criança demonstra ter apreendido a explicação, mas a segunda não reproduz bem esse relato, demonstrando não haver compreendido o funcionamento da torneira a partir do relato da "explicadora".

Contrapondo-se às interpretações piagetianas, Lacan observa que "em se tratando da torneira como causa, não se dá uma boa explicação ao dizer que o manuseio da torneira ora abre, ora fecha. A torneira foi feita para fechar" (LACAN, 1962-1963/2005, p. 314-315). Ao interrogar o que falta na transmissão da "explicadora" à "reprodutora", assinala o desinteresse da segunda criança pelos mecanismos subjacentes à torneira, descritos pelo experimentador em sua explicação. O que de fato interessa à criança é "o efeito da torneira, como sendo uma coisa que fecha, e o resultado, ou seja, que, graças à torneira, pode-se encher uma bacia de água sem que ela transborde." (ibidem, p. 315). Nessa relação da torneira com seu efeito, situa-se a dimensão da causa, que tem como efeito o represamento da água, relação que lastreia a cadeia significante em jogo para a criança. Conforme Lacan, Piaget desconhece o que há de interessante para uma criança numa torneira, a saber, os desejos despertados por esse objeto hidráulico, como, por exemplo, de urinar.

De acordo com Santiago (2010), Lacan lança mão dessas observações experimentais de Piaget sobre a passagem, na criança, da "linguagem egocêntrica" à "linguagem socializada" para demonstrar que, no lugar da estrutura de intencionalidade, deve ser apreendida a estrutura de causalidade, na medida em que o objeto passa a ser compreendido como o que está "por trás" do desejo, como causa. Para Santiago, Lacan interpreta Piaget ao afirmar que, se este não pode captar o que está em jogo para a criança em relação à torneira, quer dizer, sua função de causa, isso se explica porque Piaget nada sabe sobre a libido, sobre o gozo, sobre o modo como a causa opera na subjetividade (SANTIAGO, 2010).

Percebe-se que, nesse momento, a obra de Piaget é uma referência importante para as reflexões de Lacan sobre o pensamento. No entanto, a perspectiva piagetiana é insuficiente para a abordagem lacaniana do conceito porque desconsidera a causalidade em jogo no pensamento. Lacan recorre, então, a outros interlocutores em sua elaboração sobre o pensamento conceitual - tal como Vygotsky (1931/2012) com sua tese sobre a formação dos conceitos na puberdade.

Pelo fato de falar, o sujeito "acredita atingir o conceito, isto é, acredita poder apreender o real por um significante que comanda esse real de acordo com sua causação íntima" (LACAN, 1962-1963/2005, p. 323). Se Lacan acompanha Vygotsky e localiza o verdadeiro acesso aos conceitos na puberdade, presume-se que, antes disso, a criança apenas acredita atingi-lo, não o acessando. Para o verdadeiro acesso ao conceito, é indispensável um ponto de inflexão na relação do sujeito com a falta, um salto lógico que independe da atribuição de sentido e da dimensão da compreensão, como pressuposta por Piaget.

A maturação do objeto $a$ torna patente para o sujeito a dissimetria entre os sexos e a hiância inerente à sexualidade. Na puberdade, a promoção do significante fálico é acompanhada por intensa angústia em face das exigências do supereu. As expectativas sobre o nível genital são, de saída, marcadas pela insatisfação, e o objeto $a$ tende a comandar a subjetividade em sua vertente mais-de-gozar. É nesse ponto que o limite se faz necessário, como delimitador do gozo que excede o sujeito. 0 "momento-limite complexual” (ibidem, p. 282), a passagem ao pensamento conceitual, condiz com uma apreensão de saber inédita para o sujeito, a subjetivação da diferença sexual. O significante fálico, ao atualizar para o sujeito a lógica da castração, vai comandar a relação conceitual, abrindo-se a possibilidade da própria conceituação.

A associação entre a capacidade do pensamento em conceitos e a puberdade volta a ser apontada por Lacan (1964-1965) no seminário Problemas cruciais para a psicanálise, numa breve menção a Vygotsky (19301931/2012), dessa vez explicitada. As significativas transformações ocasionadas pela sexualidade na puberdade promovem, para ambos os autores - Vygotsky e Lacan -, um deslocamento subjetivo que é da ordem da lógica, não do sentido. Lacan sublinha que "Piaget e Vygotsky ilustram, do primeiro para o segundo, o ganho que se obtém ao repelir qualquer hipótese psicológica das relações do sujeito com a linguagem, mesmo quando é da criança que se trata" (LACAN, 1966/2003, p. 206-207), esclarecendo, assim, sua crítica à 
perspectiva piagetiana e sua escolha pela proposta vygotskyana na abordagem do pensamento e do conceito. A referência ao conceito nessa conjuntura como ponto de inflexão na passagem adolescente deve-se, em nossa leitura, à necessidade de depuração da atribuição de sentido na atualização subjetiva que se passa nesse momento, quando se coloca para o sujeito um saber acerca da sexualidade que é da ordem de um não saber. Para avançar nesse entendimento, passemos a outros contextos da teorização de Lacan nos quais um autor do campo do Lógica será de grande importância para a abordagem do conceito.

\section{O CONCEITO E O OBJETO: ECOS DE FREGE}

O problema do conceito na obra de Lacan nos remete a seu interesse pelo pensamento de Frege ${ }^{2}$, que idealiza a "conceitografia" como formalização da lógica para apreensão da verdade científica. Seu esforço visa depurar do pensamento qualquer influência psicológica, intuitiva ou empírica, a fim de chegar a uma "linguagem formular do pensamento puro" (FREGE, 1879/2009, p. 45). Com esse rigor, intenta se esquivar do "obstáculo da insuficiência da linguagem" (idem) e da limitação da percepção humana na empiria para potencializar o alcance do pensamento puro na abordagem e resolução dos problemas, especialmente da matemática. Para abarcar a aritmética pela lógica sem incorrer nos equívocos da linguagem, Frege estabelece o número no mesmo plano da razão: toma-o como "conceito de número", evitando a interferência dos sentidos ou da intuição na transposição da categoria do número para o domínio do pensamento.

A crítica de Frege ao psicologismo é cara a Lacan, bem como o empenho em se valer da depuração da lógica como recurso frente aos equívocos da linguagem, o que, em certa medida, conflui com o rechaço lacaniano à atribuição de sentido. Lacan se utiliza de algumas ferramentas fornecidas por Frege, tais como os quantificadores que Ihe serão de grande valia na formulação do matema da sexuação e as concepções do um e do zero. Todavia, como de costume nas apropriações que esse psicanalista faz de outros sistemas de pensamento, trata-se de um uso subversivo das indicações de Frege. Interessa-nos localizar alguns pontos dessa obra que podem lançar luz sobre a abordagem lacaniana do conceito. Frege () escreve:

A palavra "conceito" é empregada de diversos modos; por vezes, em sentido psicológico, por vezes, em sentido lógico e, por vezes talvez, numa confusa mistura de ambos. Essa liberdade, porém, se vê naturalmente limitada pela exigência de que, uma vez adotado um uso para essa palavra, este deva ser mantido. $O$ que decidi foi ater-me a um uso puramente lógico. (FREGE, 1892/2009, p. 111).

Parece-nos que Lacan se serve dessa orientação em seu logicismo, que abarca as relações do sujeito com o conceito, atrelado ao objeto $a$. Sobre o conceito e o objeto, Frege afirma:

Tomando "sujeito" e "predicado" em seu sentido linguístico, podemos em resumo dizer: um conceito é a referência de um predicado, enquanto que um objeto é o que nunca pode ser a referência total de um predicado, embora possa ser a referência de um sujeito. (Ibidem, p. 118).

Para Frege, o comportamento do conceito é essencialmente predicativo, de maneira que só pode ser substituído por um outro conceito, nunca por um objeto. "Um conceito nunca poderá ser asserido de um objeto; pois um nome próprio nunca pode ser uma expressão predicativa, embora possa ser parte de uma tal expressão" (ibidem, p. 120).

Lacan (1965-1966) se reporta a Frege ao tratar do ponto de orifício entre a verdade e o saber, afirmando que, para esse problema, o matemático tenta uma solução através de sua concepção de conceito. Conforme o psicanalista, o "valor de verdade" é depreendido por certa redução ou limitação, que é o que Frege extrai de sua teoria do número. Na leitura lacaniana, o conceito é centrado sobre algo a que pode ser dado um nome

2 Vale informar que o problema do conceito para Lacan aparece em pontos anteriores de sua obra, em debates com outros pensadores além de Frege, como Kant, e sua razão pura, e a lógica de Russell (conforme citados em LACAN, 1961 1962, entre outras obras). Não obstante, interessa-nos particularmente a referência a Frege em função da articulação entre conceito e objeto. 
próprio. Nisso se revela o caráter subjetivo - no sentido que a psicanálise dá ao termo sujeito - do que, para Frege, caracteriza-se como o objeto da ciência. Lacan aproxima esse valor de verdade ao objeto a, que opera a apreensão do saber também para os sujeitos da ciência a partir de sua relação à questão da verdade.

Ainda sobre a distinção entre conceito e objeto, Frege afirma que "uma asserção feita a um conceito nunca convém a um objeto" (FREGE, 1892/2009, p. 121). Para ele, os objetos "caem" sob os conceitos. Até aqui, percebe-se a fonte lógica para as elucubrações de Lacan sobre o conceito. Mas o psicanalista vai além, pois se apoia nessa lógica para postular uma relação conceitual que se dá sobre um vazio, o que vai na contramão do projeto fregiano, que visa, em última instância, abolir qualquer lacuna para garantia de univocidade. É o que lemos nesta passagem em que Frege justifica seu método para garantir o acesso à verdade na matemática:

A via que segui [...] foi a seguinte: tentei reduzir o conceito de sucessão em uma sequência à noção da consequência lógica, para daí poder estabelecer o conceito de número. Para evitar que nessa tentativa se intrometesse inadvertidamente algo de intuitivo, cabia tudo reduzir a uma cadeia inferencial carente de qualquer lacuna. (FREGE, 1879/2009, p. 44).

Ora, é precisamente à lacuna que Lacan (1962-1963/2005) vai recorrer para problematizar a conceituação. Quanto a Frege, é incontestável sua influência nessa teorização, na medida em que abre a Lacan "a possibilidade de um modelo de escritura formal do real, também independente do recurso à intuição sensível e à dimensão imaginária do sentido" (IANNINI, 2012, p. 241).

Segundo lannini (2012), o ponto mais importante da apropriação lacaniana do pensamento de Frege é a demonstração, por contraste, da irredutibilidade do caso ao conceito. A inferência do um do conjunto vazio, por Frege, faz pensável homologamente no campo da psicanálise que o ser do sujeito provém da sutura de uma falta (LACAN, 1966/2003), o que "torna obsoleto o recurso a um esquema de causação psicológica do sujeito" (IANNINI, 2012, p. 242). Isto é, a causação do sujeito não é psicológica, é lógica.

A causação lógica do sujeito é uma das teses principais a que Lacan se dedica a atestar no decorrer do seminário Problemas cruciais para a psicanálise, obra da qual extraímos uma passagem que mostra o ponto do recurso lacaniano a Frege:

O sujeito seria, em suma, reconhecível naquilo que se revela, no pensamento matemático, estreitamente ligado ao conceito de falta, a este conceito cujo número é zero. É impressionante a analogia deste conceito com o que tenho tentado formular para vocês sobre a posição do sujeito enquanto que aparecendo e desaparecendo em uma pulsação sempre repetida, como efeito, efeito do significante, efeito sempre evanescente e renascente. É impressionante a analogia dessa metáfora com o conceito tal como a reflexão de um aritmético filósofo, [...] Frege é levado a fazer partir, necessariamente, do apoio, da contribuição deste conceito, cuja atribuição de número é zero, para daí fazer surgir este um, ele também inextinguível, sempre se esvaindo para, em sua repetição, se somar a si mesmo, mas numa unidade de repetição da qual se pode dizer, dela também, que nós aí tocamos, que jamais se reencontra, na medida em que ela progride, aquilo que ela perdeu. (LACAN, 1964-1965, p. 177).

Nota-se, aí, o valor que Lacan confere às ideias fregianas para o respaldo de suas reflexões sobre a posição subjetiva e a causação do sujeito.

Iannini demonstra como Lacan segue Frege apenas até certo ponto. De acordo com lannini, o conceito fregiano pode ser representado por uma função não saturada por um argumento, cuja referência é um valor de verdade. Já Lacan, desde a proposição da significação do falo, define a função que supre a relação sexual em termos de ser ou ter o falo. Iannini esclarece:

Num primeiro momento, parece que a conceitografia fornece uma maneira de escrever a relação sexual como a função insaturada Фx. Mas é aqui que a conceitualização encontra seu limite, pois um existente real - eu, você -, ao saturar a função, não cai sob seu conceito, pelo menos não integralmente. [...]. Assim, não basta pôr um conceito como função insaturada e determinar meios de reconhecimento de objetos que servem como 
argumento para aquela função, pois um existente singular sempre é irredutível à função designada pelo conceito. (IANNINI, 2012, p. 248-249).

Esse autor acrescenta que "uma existência opõe-se ao universal da função conceitual, no caso a função fálica" (ibidem, p. 249), de modo que uma proposição universal só pode se escrever ao apagar o que no sujeito o determina como sujeito. Esse ponto de insubmissão ao conceito é o objeto $a$ - que, diferentemente dos demais objetos, não "cai" sob o conceito, nos termos de Frege. É aí que a démarche lacaniana tensiona a noção de conceito fregiana, ao mesmo tempo que dela se aproxima. lannini frisa a impossibilidade inerente ao objeto $a$ de se instituir de forma predicativa. Para ele, "assumir a divisão significa [...] saber que o objeto $a$ não pode ser inferido por vias psicológicas" (IANNINI, 2012, p. 251), assim como o número não é resultado de processos psíquicos.

Continuando nosso rastreio, no seminário $O$ sinthoma, Lacan aborda o pensamento conceitual da seguinte maneira:

O objeto que chamei de pequeno $a$ é, com efeito, apenas um único e mesmo objeto. Eu lhe atribuí o nome de objeto em razão do seguinte: o objeto é $o b$, obstáculo à expansão do imaginário concêntrico, isto é, englobante. O objeto é concebível, isto é, apreensível com a mão - é a noção de Begriff - à maneira de uma arma. [...] essa arma, longe de ser um prolongamento do braço, é desde a origem uma arma de arremesso. Ninguém esperou as balas para lançar um bumerangue. (LACAN, 1975-1976/2007, p. 83).

Segundo Safatle, depreende-se daí que "a apreensão conceitual é algo como a apreensão com a mão, manipulação instrumental permitida pelo saber do objeto - o que não deixa de fazer jus ao termo alemão Begriff, no qual vemos ressoar o greifen que indica: agarrar, alcançar"3 (SAFATLE, 2006, p. 266). Ele enfatiza o caráter de resistência à universalização que o objeto confere ao conceito, que indica o que há de real no objeto:

Se o objeto é determinado como o que coloca obstáculos às mãos do conceito, é porque a ação do conceito é indissociável de uma operação de produção de consistência própria ao Imaginário. Para Lacan, a função do conceito consiste sobretudo em dar consistência ao objeto unificando [...] o múltiplo da experiência por meio de um processo que anula a não-identidade. (Ibidem, p. 268).

Com isso, inferimos que a puberdade viabiliza o acesso aos conceitos por se instituir, entre o sujeito e os objetos da realidade, um objeto que faz limite à expansão imaginária generalizante, escancarando a irredutibilidade do real à linguagem. Diante da lacuna que faz obstáculo à consistência da apreensão conceitual imaginária - não verdadeira, a partir do que Lacan (1962-1963/2005) propõe - são necessários, então, outros recursos, instrumentos de apreensão que são da ordem da invenção.

A associação entre o Begriff e a apreensão, no sentido corpóreo do termo, aparece em outros contextos da obra de Lacan. No seminário Le non-dupes errent (1973-1974), o autor alude ao Begriff como o "que se apreende bem" (s.p.), ao que se toma na mão. Já no seminário R.S.I. (1974-1975), uma pontuação nos auxilia a compreender a articulação entre a lógica fálica e o conceito. Numa explanação em que as teorias de Frege sobre o um e o conjunto vazio são novamente evocadas, Lacan afirma:

O falo, pois, é o Real, sobretudo enquanto se o elide. [...] Há um Real que ex-siste com esse falo, que se chama gozo, mas é antes a consistência, é o conceito, se posso assim dizer, do falo. Com o conceito faço eco à palavra Begriff, o que não é tão mau, pois, em suma, esse falo é o que se pega com a mão. Há algo no conceito que não deixa de ter relação com esse anúncio, essa prefiguração de um órgão que não é ainda tomado como consistência, mas como apêndice, e que é bastante bem manifestado naquilo que prepara o homem. (LACAN, 1974-1975, s.p.).

Nessa elaboração, Lacan alude à masturbação, acrescentando uma observação sobre o fato de que o macaco também se masturba, "e é nisso que se parece com o homem" (s.p.). Daí decorre, para o autor, que

${ }^{3}$ No alemão, Begriff é “conceito", "noção", “ideia”. Já o verbo greifen corresponde a "agarrar", "pegar em”, "tocar" (um instrumento musical), "meter a mão" (no bolso), entre outros (IRMEN, 1994). 
"no conceito, há sempre algo da ordem da macaquice" (s.p.), comentário pitoresco que podemos compreender pelo dado de que os macacos também constroem e utilizam instrumentos, ferramentas. Mas, diversamente dos humanos que chegam à maturação pubertária, os macacos não formam conceitos. Lacan vai situar a distinção radical entre esses animais e os seres humanos na consistência do falo tanto para homens quanto para mulheres, para quem o falo consiste "valendo sua ausência" (s.p.). É, pois, a falta que opera a sexualidade humana. E a formação do conceito - esse instrumento de apreensão que concerne à lógica e ao corpo - está relacionada à tomada de posição do sujeito na sexualidade.

\section{CONCLUSÃO}

Esse ponto de encontro entre Lacan e Frege, permeado pela leitura lacaniana de Vygotsky, permite compreender melhor o que está em jogo na assunção conceitual inaugurada pela puberdade (LACAN, 19621963/2005). O verdadeiro acesso aos conceitos nesse tempo do sujeito se faz possível a partir de uma equação que conjuga a significação do falo com a irrupção do real do despertar pubertário, resultando naquilo que Lacan designa como a maturação do objeto $a$. Dessa equação deriva a emergência de um saber sobre a não relação sexual, que se faz questão para o sujeito de maneira inédita. Trata-se de um saber enigmático, perturbador, mas que, paradoxalmente, abre caminho para a capacidade de conceituação. A maturação do objeto $a$ torna patente ao sujeito a hiância, o descompasso, a dissimetria radical na relação com a alteridade, pois há um resto, um ponto irredutível. E essa apreensão acontece no corpo, lugar da libido e da angústia.

Para avançar nesse entendimento, vejamos o que Lacan diz sobre o conceito na obra Os quatro conceitos fundamentais da psicanálise. Nesse seminário, o conceito é associado à possibilidade de "formulação", de se pôr em fórmulas que modulam o deslizamento do objeto. Há uma articulação entre, de um lado, a correspondência das formas diversas do objeto a com a função central e simbólica do (- $\phi)$ e, de outro, a conotação (LACAN, 1964/1998, p. 24). Lacan afirma:

Nossa concepção do conceito implica ser este sempre estabelecido numa aproximação que não deixa de ter relação com o que nos impõe, como forma, o cálculo infinitesimal. Se o conceito se modela, com efeito, por uma aproximação da realidade que ele foi feito para apreender, só por um salto, por uma passagem ao limite, é que ele chega a se realizar. (Ibidem, p. 25).

Embora a puberdade não seja mencionada nesse trecho, sabemos, desde o seminário A angústia, que ela é imprescindível para essa "passagem ao limite", possível graças a um salto lógico que requer familiaridade com a dimensão da falta, um salto sobre o infinito. A captação conceitual envolve um cálculo que depende da certeza da perda, da queda de certos véus que a infância até então proporciona ao sujeito. Momento angustiante da "perda da inocência", como denota o chavão retórico, a puberdade inaugura a apreensão da realidade por uma nova forma de nomeação dos objetos que conta com um resíduo, com a presença irreparável da falta.

A adolescência é o tratamento simbólico do real que emerge com a puberdade sob a forma de um enigma, do não saber radical sobre a sexualidade. Esse tempo subjetivo condiz com um trabalho psíquico delicado em que se efetua o desligamento da autoridade dos pais e a travessia ao Outro social em seu sentido mais amplo. Nessa complexa operação, é necessária a construção de um saber-fazer com isso que acomete o corpo. A partir das indicações de Lacan acerca da formação dos conceitos na puberdade, concluímos que a entrada no pensamento lógico é uma forma de maturação que pode dar suporte ao sujeito nessa difícil transição. A ferramenta conceitual e sua função lógica propiciam ao adolescente ir buscar no Outro uma resposta própria, uma invenção singular que lhe permite um endereçamento à vida adulta, um deslocamento do ponto angustiante de enigma a uma posição inventiva, na qual alguma saída é possível.

A invenção pode proporcionar as mais variadas manifestações na adolescência, que têm em comum um elemento novo - um novo apenso a um saber indissociável do corpo desde a constituição do sujeito. Esse novo pode ser compreendido como um saber-fazer com o vazio e com o sintoma, um saber haver-se com o 
gozo, um modo singular de contornar o vazio, que a ferramenta conceitual - uma ferramenta nova ao adolescente, como vimos - permite construir. Evidentemente, trata-se, para muitos sujeitos, de um saberfazer falho, precário, instável, que vai derrapar muitas vezes diante do real que se presentifica reiteradamente nessa fase. Ainda assim, quando acolhida e reconhecida no encontro do adolescente com o Outro, a invenção, com suporte no pensamento conceitual, pode configurar o detalhe, mesmo ínfimo, que garante uma operação da adolescência.

Recebido em 5 de fevereiro de 2017, Aprovado em: 21 de agosto de 2017.

\section{REFERÊNCIAS}

COELHO DOS SANTOS, T. Sobre a clínica da psicanálise de orientação lacaniana: dos impasses da sexuação à invenção do parceiro-sinthoma. Ágora (UFRJ), v. 12, n. 1. Rio de Janeiro, 2009. Disponível em: <http://dx.doi.org/10.1590/S1516-14982009000100001>. Acesso em: 8 out. 2016.

FREGE, G. Conceitografia, "Prefácio" (1879). In: USP, 2009. Lógica e filosofia da linguagem. São Paulo: USP, 2009

Sobre o conceito e o objeto (1892). In: Lógica e filosofia da linguagem. São Paulo:

FREUD, S. Além do princípio do prazer (1920). In: História de uma neurose infantil, Além do princípio do prazer e outros textos. V. 14. São Paulo: Companhia das Letras, 2010, p. 161-239.

Análise da fobia de um garoto de cinco anos (1909). In: O delírio e os sonhos na Gradiva, Análise da fobia de um garoto de cinco anos e outros textos. V. 8. São Paulo: Companhia das Letras, 2015, p. 123- 284.

Três ensaios sobre a teoria da sexualidade (1905). In: Um caso de histeria, Três ensaios sobre a sexualidade e outros trabalhos (1901-1905). Rio de Janeiro: Imago, 1996. P. 119-229. (Ed. standard brasileira das obras psicológicas completas de Sigmund Freud, 7)

IANNINI, G. Estilo e verdade em Jacques Lacan. Belo Horizonte: Autêntica, 2012.

IRMEN, F. Langenscheidts Taschenwörterbuch: Der Portugiesischen und Deutschen Sprache. Berlim: Langenscheidt, 1994.

LACAN, J. A angústia (1962-1963). Rio de Janeiro: Jorge Zahar, 2005. (O seminário, 10).

A identificação (1961-1962). Rio de Janeiro: Jorge Zahar, inédito. (O seminário, 9).

A significação do falo (1958). In: Escritos. Rio de Janeiro: J. Zahar, 1998. P. 692-703.

Le non-dupes errent (1973-1974). Inédito. (O seminário, 21). Foi utilizada a edição do Centro de Estudos Freudianos de Recife.

L'objet de la psychanalyse (1965-19656). Inédito. (O seminário, 13). O exemplar utilizado foi editado por M. Roussan e colaboradores. Paris, 2006.

O sinthoma (1975-1976). Rio de Janeiro: Jorge Zahar, 2007. (O seminário, 23).

Os quatro conceitos fundamentais da psicanálise (1964). Rio de Janeiro: Jorge Zahar, 1998. (O seminário, 11).

Prefácio a $O$ despertar da primavera (1974). In: Outros escritos. Rio de Janeiro: J. Zahar, 2003. P. 557-559.

Problemas cruciais para a psicanálise (1964-1965). Rio de Janeiro: Jorge Zahar, inédito. (O seminário, 12). Foi utilizada a edição do Centro de Estudos Freudianos de Recife.

Problemas cruciais para a psicanálise: resumo do seminário de 1964-65 (1966). In: Outros escritos. Rio de Janeiro: J. Zahar, 2003. P. 206-209.

R.S.I. (1973-1974). Inédito. (O seminário, 22). Foi utilizada a edição do Centro de Estudos Freudianos de Recife.

Subversão do sujeito e dialética do desejo no inconsciente freudiano (1960). In: Escritos. Rio de Janeiro: J. Zahar, 1998.

PIAGET, J. A linguagem e o pensamento na criança (1923). São Paulo: Martins Fontes, 1999.

SAFATLE, V. A paixão do negativo: Lacan e a dialética. São Paulo: UNESP, 2006.

SANTIAGO, J. Lacan y el grifo de Piaget: sobre el objeto-causa del deseo en el Seminario 10, de Jacques Lacan. In: BERENGUER, E. et al. La angustia en Freud y Lacan: cuerpo, significante y afecto. Nueva Escuela Lacaniana de Psicoanálisis. Bogotá: Nel Bogotá, 2010, v. 2, p. 143-157. 
VYGOTSKY, L. El desarollo del pensamiento del adolescente y la formación de conceptos (1931). In: . Paidología del adolescente: obras escogidas, 5. Madrid: Machado Libros, 2012, p. 47-116.

\section{Daniela Teixeira Dutra Viola}

Professora no Departamento de Psicologia, Universidade Federal de São João del-Rei (UFSJ), São João delRei/MG, Brasil, daniela, dutraviola@gmail.com 